\title{
BZIP Protein
}

National Cancer Institute

\section{Source}

National Cancer Institute. bZIP Protein. NCI Thesaurus. Code C17582.

Bipartite DNA binding protein containing a basic region that directly interacts with DNA, and a leucine zipper that mediates dimerization through contacts with a protein partner. 